University of Nebraska - Lincoln

DigitalCommons@University of Nebraska - Lincoln

Agronomy \& Horticulture - Faculty Publications

Agronomy and Horticulture Department

2006

\title{
Performance of WeedSOFT for Predicting Soybean Yield Loss
}

Shawn M. Hock

University of Nebraska-Lincoln

Stevan Z. Knezevic

University of Nebraska-Lincoln, sknezevic2@unl.edu

Alex Martin

University of Nebraska-Lincoln, amartin2@unl.edu

John L. Lindquist

University of Nebraska-Lincoln, jlindquist1@unl.edu

Follow this and additional works at: https://digitalcommons.unl.edu/agronomyfacpub

Part of the Plant Sciences Commons

Hock, Shawn M.; Knezevic, Stevan Z.; Martin, Alex; and Lindquist, John L., "Performance of WeedSOFT for Predicting Soybean Yield Loss" (2006). Agronomy \& Horticulture -- Faculty Publications. 372.

https://digitalcommons.unl.edu/agronomyfacpub/372

This Article is brought to you for free and open access by the Agronomy and Horticulture Department at DigitalCommons@University of Nebraska - Lincoln. It has been accepted for inclusion in Agronomy \& Horticulture -Faculty Publications by an authorized administrator of DigitalCommons@University of Nebraska - Lincoln. 


\title{
Performance of WeedSOFT for Predicting Soybean Yield Loss ${ }^{1}$
}

\author{
SHAWN M. HOCK, STEVAN Z. KNEZEVIC, ALEX R. MARTIN, and JOHN L. LINDQUIST ${ }^{2}$
}

\begin{abstract}
Decision support systems (DSSs) have been developed to assist producers and consultants with weed management decisions. WeedSOFT is a DSS currently used in several states in the northcentral region of the United States. Accurate estimates of crop yield loss due to weed interference are required for cost-effective weed management recommendations. WeedSOFT uses competitive indices (CIs) to predict crop yield loss under multiple weed species, weed densities, and relative times of weed emergence. Performance of several WeedSOFT versions to predict soybean yield loss from weed competition was evaluated using CI values in WeedSOFT version 9.0 compared to new CI values calculated from weed dry matter, weed volume, and soybean yield loss in two soybean row spacings (19 and $76 \mathrm{~cm}$ ) and two relative weed emergence times (at soybean emergence and first trifoliate leaf stage). Overall, new CI values improved predictions of soybean yield loss by as high as $63 \%$. It was especially true with using new CI values based on yield loss compared to those based on weed dry matter or weed volume. However, there were inconsistencies in predictions for most weed species, suggesting that additional modifications are needed to further improve soybean yield loss predictions.

Nomenclature: Soybean, Glycine max (L.) Merr.

Additional index words: Crop modeling, competition, decision support systems, simulation, Abutilon theophrasti, Amaranthus retroflexus, Amaranthus rudis, Ambrosia trifida, Echinochloa crusgalli, Helianthus annuus, Setaria faberi, Setaria glauca, Xanthium strumarium, ABUTH, AMARE, AMATA, AMBTR, ECHCG, HELAN, SETFA, SETLU, XANST.

Abbreviations: AE, average error; ACI, adjusted competitive index; CI, competitive index; DM, WeedSOFT version based on weed dry matter; DSS, decision support systems; RCBD, randomized complete block design; TCL, total competitive load; TDM, total dry matter; V1, soybean first trifoliate leaf stage; VE, soybean emergence; VP, soybean planting; VOL, WeedSOFT version based on weed volume; WS, WeedSOFT version 9.0; YL, WeedSOFT version based on yield loss.
\end{abstract}

\section{INTRODUCTION}

Decision support systems (DSSs) have been developed to assist practitioners with weed management decisions. Many factors can be incorporated into the DSSs, including weed species, density, weed emergence time, herbicide efficacy, cost effectiveness, and environmental safety. WeedSOFT is one such DSS, which was not specifically developed to model weed-crop interference process, but to assist producers and consultants with weed management decisions, and as an educational tool. It is currently being adopted for use in the north-central United States including Illinois, Indiana, Kansas, Michigan, Missouri, Nebraska, and Wisconsin (Neeser et al. 2004).

\footnotetext{
${ }^{1}$ Received for publication April 30, 2005, and in revised form November 11, 2005. Published as University of Nebraska Agricultural Research Division Journal Series 14933.

${ }^{2}$ First, third, and fourth authors: Graduate Research Assistant, Professor, and Associate Professor, University of Nebraska, Lincoln, NE 68583; second author: Associate Professor, University of Nebraska, Concord, NE 68728. Corresponding author's E-mail: sknezevic2@unl.edu.
}

WeedSOFT contains four modules. The first, EviroFX, computes site- and herbicide-specific groundwater contamination risk. MapVIEW is a series of color-coded Nebraska county maps depicting groundwater vulnerability to herbicide contamination, thus promoting environmentally sound use of herbicides. WeedVIEW provides weed images to facilitate proper weed identification. The final module, ADVISOR, provides yield loss estimates and weed management recommendations, including a list of herbicide programs based on weed control efficacy (Neeser et al. 2004). The main purpose of WeedSOFT is to provide a list of management recommendations based on input variables such as crop species, crop growth stage, densities of weed species, and weed growth stage (Neeser et al. 2004). Yield loss is calculated using a competitive index (CI) value for each weed species. The CI is a relative measure of weed competitiveness, where a larger value indicates a more competitive weed. This concept also was used in several DSSs, 
Table 1. Values for competitive indices (CIs) and adjusted competitive indices (ACIs) in WeedSOFT version 9.0, and ACI values based on yield loss (YL), weed volume (VOL), and weed dry matter (DM).

\begin{tabular}{|c|c|c|c|c|c|c|c|c|c|c|c|c|c|c|c|c|c|}
\hline \multirow{3}{*}{$\begin{array}{l}\text { Weed } \\
\text { code }^{\mathrm{a}}\end{array}$} & \multirow[b]{3}{*}{$\mathrm{CI}^{\mathrm{b}}$} & \multicolumn{4}{|c|}{$\mathrm{ACI}^{\mathrm{c}}$} & \multicolumn{4}{|c|}{$Y^{d}$} & \multicolumn{4}{|c|}{$\mathrm{VOL}^{\mathrm{e}}$} & \multicolumn{4}{|c|}{$\mathrm{DM}^{\mathrm{f}}$} \\
\hline & & \multicolumn{2}{|c|}{$\mathrm{SRS}^{\mathrm{g}}$} & \multicolumn{2}{|c|}{ RWET $^{\mathrm{h}}$} & \multicolumn{2}{|c|}{ SRS } & \multicolumn{2}{|c|}{ RWET } & \multicolumn{2}{|c|}{$76 \mathrm{~cm}$} & \multicolumn{2}{|c|}{$19 \mathrm{~cm}$} & \multicolumn{2}{|c|}{$76 \mathrm{~cm}$} & \multicolumn{2}{|c|}{$19 \mathrm{~cm}$} \\
\hline & & $19 \mathrm{~cm}$ & $76 \mathrm{~cm}$ & VE & V1 & $76 \mathrm{~cm}$ & $19 \mathrm{~cm}$ & VE & V1 & VE & V1 & VE & V1 & VE & V1 & VE & V1 \\
\hline HELAN & 10.0 & 0.8 & 1.0 & 1.0 & 0.6 & 1.0 & 0.8 & 1.0 & 0.6 & 1.0 & 0.4 & 0.6 & 0.1 & 1.0 & 0.4 & 0.7 & 0.2 \\
\hline XANST & 5.0 & 0.8 & 1.0 & 1.0 & 0.6 & 1.1 & 1.3 & 1.4 & 0.9 & 1.6 & 0.3 & 0.6 & 0.2 & 0.7 & 0.2 & 0.5 & 0.2 \\
\hline ABUTH & 4.2 & 0.8 & 1.0 & 1.0 & 0.6 & 0.8 & 0.7 & 1.2 & 0.8 & 0.3 & 0.2 & 0.1 & 0.1 & 0.6 & 0.2 & 0.3 & 0.1 \\
\hline AMBTR & 3.0 & 0.8 & 1.0 & 1.0 & 0.6 & 0.8 & 0.8 & 1.1 & 0.4 & 0.4 & 0.1 & 0.1 & 0.1 & 0.6 & 0.1 & 0.3 & 0.1 \\
\hline AMARE & 2.5 & 0.8 & 1.0 & 1.0 & 0.6 & 1.5 & 1.3 & 1.9 & 0.8 & 0.4 & 0.2 & 0.2 & 0.1 & 0.4 & 0.2 & 0.3 & 0.2 \\
\hline AMATA & 2.5 & 0.8 & 1.0 & 1.0 & 0.6 & 1.0 & 0.8 & 1.5 & 0.9 & 0.4 & 0.1 & 0.2 & 0.1 & 0.2 & 0.1 & 0.1 & 0.1 \\
\hline SETFA & 2.0 & 0.8 & 1.0 & 1.0 & 0.6 & 0.3 & 0.6 & 1.0 & 0.7 & 0.1 & 0.1 & 0.1 & 0.1 & 0.1 & 0.1 & 0.1 & 0.1 \\
\hline SETLU & 1.0 & 0.8 & 1.0 & 1.0 & 0.6 & 0.3 & 1.4 & 2.3 & 0.8 & 0.1 & 0.1 & 0.1 & 0.1 & 0.2 & 0.1 & 0.2 & 0.1 \\
\hline ECHCG & 0.3 & 0.8 & 1.0 & 1.0 & 0.6 & 0.6 & 2.9 & 5.7 & 3.3 & 0.4 & 0.2 & 0.1 & 0.1 & 0.5 & 0.4 & 0.6 & 0.3 \\
\hline
\end{tabular}

\footnotetext{
${ }^{a}$ Weed code: HELAN, common sunflower; XANST, common cocklebur; ABUTH, velvetleaf; AMBTR, giant ragweed; AMARE, redroot pigweed; AMATA, common waterhemp; SETFA, giant foxtail; SETLU, yellow foxtail; ECHCG, barnyardgrass.

${ }^{\mathrm{b}} \mathrm{CI}$, original CI values in WeedSOFT version 9.0.

c ACI, ACI modifiers in WeedSOFT version 9.0.

${ }^{d}$ YL, ACI based on soybean yield losses caused by respective weed species.

${ }^{\circ} \mathrm{VOL}, \mathrm{ACI}$ values based on weed volume.

${ }^{\mathrm{f}} \mathrm{DM}$, ACI values based on weed dry matter.

${ }^{g}$ SRS, soybean row spacing (76 and $19 \mathrm{~cm}$ ).

${ }^{\text {h }}$ RWET, relative weed emergence time, at soybean emergence (VE) and soybean first trifoliate leaf stage (V1).
}

including HERB (Coble and Mortensen 1992; Wilkerson et al. 1991), NebHERB (Mortensen et al. 1993), GWM (Wiles et al. 1996), and HADSS (Sturgill et al. 2001) to calculate yield loss. Current CI values in WeedSOFT have been derived from local or regional field research and expert opinion (Neeser et al. 2004). Expert opinions differ, and results of crop-weed interference studies can vary among years and locations (Bauer et al. 1991; Chikoye and Swanton 1995; Cousens et al. 1988; Knezevic et al. 1994, 1995; Lindquist and Mortensen 1999; Lindquist et al. 1996; Lotz et al. 1996), whereas CI values also can vary with environmental, edaphic, and agronomic variables (White and Coble 1997).

Yield loss calculations in WeedSOFT are modified using an adjusted competitive index (ACI) value to account for relative time of weed emergence and crop row spacing (Neeser et al. 2004). WeedSOFT uses a standard ACI modifier across all weed species (Table 1) and is calculated utilizing:

$$
\mathrm{ACI}_{i}=\mathrm{CI}_{i} \mathrm{CIM}_{i}
$$

where $\mathrm{CI}_{i}$ is the $\mathrm{CI}$ for a weed species $(i)$ in a given crop and $\mathrm{CIM}_{i}$ is a modifier that is determined by the weed (i) and crop growth stages (Neeser et al. 2004).

The ACI for each weed species is then used, along with density of that species, to calculate the total competitive load (TCL) for all $n$ species present in a field:

$$
\mathrm{TCL}=\Sigma\left(\mathrm{D}_{i} \times \mathrm{ACI}_{i}\right)
$$

where $\mathrm{D}$ is the density and $\mathrm{ACI}_{i}$ is the $\mathrm{ACI}$ for weed species $i$ (Neeser et al. 2004). Calculation of predicted yield loss as a function of TCL within WeedSOFT is made using a rectangular hyperbola with both linear and nonlinear components (Neeser et al. 2004), which suggest that the yield loss function is linear at low weed densities (e.g., up to $25 \%$ of the total soybean yield loss), and then becomes curvilinear, which is depicted by rectangular hyperbola (Cousens 1985).

Recently we reported a new set of CI values based on a multi-weed species study in soybean (Hock et al. 2005), which provided a unique opportunity for testing performance of WeedSOFT for predicting the effects of weed interference on soybean yield losses. Although Rankins et al. (1998) suggested that changing CI values in HERB (currently HADSS) did not improve yield loss predictions because environmental conditions during the growing season cannot be predicted, the CI values were useful in calculating weed competition levels from a multispecies weed complex (White and Coble 1997). The objective of this study was to test the accuracy of WeedSOFT in predicting soybean yield losses using current CI values in WeedSOFT (version 9.0) compared to those calculated from weed dry mater, weed volume, and soybean yield loss as reported in Hock et al (2005).

\section{MATERIALS AND METHODS}

Experimental Data. Field experiments were conducted in 2002 and 2003 at the University of Nebraska Haskell Agricultural Laboratory in Concord, NE $\left(42.37^{\circ} \mathrm{N}\right.$, 
HOCK ET AL.: WEEDSOFT FOR PREDICTING SOYBEAN YIELD LOSS

Table 2. Weed planting and emergence dates, and soybean leaf stage at the time of weed emergence for 2002 and 2003.

\begin{tabular}{|c|c|c|c|c|c|c|c|c|c|}
\hline \multirow[b]{3}{*}{ Cohort } & \multicolumn{3}{|c|}{ Planting date } & \multicolumn{3}{|c|}{ Emergence date } & \multicolumn{3}{|c|}{ Soybean leaf stage ${ }^{a}$} \\
\hline & \multicolumn{2}{|c|}{ Concord } & \multirow{2}{*}{$\begin{array}{c}\text { Lincoln } \\
2003\end{array}$} & \multicolumn{2}{|c|}{ Concord } & \multirow{2}{*}{$\begin{array}{c}\text { Lincoln } \\
2003\end{array}$} & \multicolumn{2}{|c|}{ Concord } & \multirow{2}{*}{$\frac{\text { Lincoln }}{2003}$} \\
\hline & 2002 & 2003 & & 2002 & 2003 & & 2002 & 2003 & \\
\hline 1 & May 31 & June 5 & May 29 & June 10 & June 16 & June 10 & VE & VE & VE \\
\hline 2 & June 10 & June 13 & June 7 & June 19 & June 25 & June 17 & V1 & V1 & V1 \\
\hline
\end{tabular}

${ }^{a}$ VE, soybean emergence; V1, first trifoliate leaf stage.

$96.97^{\circ} \mathrm{W}$ ) and in 2003 at the University of Nebraska Agricultural Research Farm in Lincoln, NE $\left(40.82^{\circ} \mathrm{N}\right.$, $96.68^{\circ} \mathrm{W}$ ) for a total of three site years. Glyphosate-resistant soybean varieties, Agripro '2502' and Agripro '2703', were planted in Concord and Lincoln, respectively, at a density of 407,000 seeds/ha in both 19- and 76-cm rows. Soybean was planted on May 31, 2002 and June 5, 2003, at Concord and on May 29, 2003, at Lincoln. Experiments were established in a factorial arrangement of treatments in a split-split plot design with four replicates. Soybean row spacing (19 or $76 \mathrm{~cm}$ ) was the main plot arranged in a randomized complete block design (RCBD), whereas the three relative weed emergence times were the subplots arranged in a RCBD within the main plots, and the 10 weed species were the subsubplots arranged in a RCBD within the subplots. The entire experimental plot was $75 \mathrm{~m}$ long and $72 \mathrm{~m}$ wide. The main plot was $75 \mathrm{~m}$ long with either 12 rows spaced $76 \mathrm{~cm}$ or 48 rows spaced $19 \mathrm{~cm}$. The three subplots were established by seeding weed seeds obtained from Valley Seed Service ${ }^{3}$ in spring 2002 at soybean planting (VP), emergence (VE), and first trifoliate leaf stage (V1). Weed planting and emergence dates for Concord and Lincoln are reported in Table 2. For each sub-subplot factor, weed species were planted in a single-weed species stand, for a total of $60 \mathrm{sub}$-subplots per replication. The six broadleaf and four grass weed species included common cocklebur (Xanthium strumarium L. \# ${ }^{4}$ XANST), common sunflower (Helianthus annuus L. \# HELAN), common waterhemp (Amaranthus rudis Sauer. \# AMATA), giant ragweed (Ambrosia trifida L.\# AMBTR), redroot pigweed (Amaranthus retroflexus L. \# AMARE), velvetleaf (Abutilon theophrasti Medic. \# ABUTH), barnyardgrass [Echinochloa crus-galli (L.) Beauv. \# ECHCG], fall panicum [Panicum dichotomiflorum (L.) Michx. \# PANDI], giant foxtail (Setaria faberi Herrm. \# SETFA), and yellow foxtail [Setaria glauca (L.) Beauv. \# SETLU]. The 10 weed species were established at

\footnotetext{
${ }^{3}$ Valley Seed Service, P.O. Box 9335, Fresno, CA 93791.

${ }^{4}$ The letters following this symbol are a WSSA-approved computer code from Composite List of Weeds, Revised 1989. Available only on computer disk from WSSA, 810 East 10th Street, Lawrence, KS 66044-8897.
}

Concord in both years. At Lincoln, fall panicum was the only weed to have poor emergence, thus data on this species were not presented. Successful establishment occurred for the first two emergence times. Each emergence subplot was $21 \mathrm{~m}$ long, which provided enough area for all 10 weed species to be grown in a subplot. Seeds of a single weed species were hand planted alternating $10 \mathrm{~cm}$ on either side of the soybean row spaced $0.5 \mathrm{~m}$ apart creating a 4-m-long single-species stand of eight plants for each weed species. Soybean growth stages were determined as described by Ritchie et al. (1993). Weeds were thinned by hand to obtain desired density of one plant per $0.5 \mathrm{~m}$ of row weekly beginning at soybean first trifioliate leaf stage. Undesirable species were removed by hand, sprayed with glyphosate as needed at a label rate, or both. Plastic jugs were temporarily placed over desired weeds to protect them from glyphosate drift.

Plant height was measured from the soil surface to the highest freestanding point of one randomly selected plant in each sub-subplot. Canopy diameter was measured at its widest point. Weed plant height and canopy diameter was measured biweekly until physiological maturity. Weed volume was defined and presented as the point of maximum cylindrical volume for each respective weed species and was calculated using the equation:

$$
V=\pi r^{2} h
$$

where $V$ is weed volume $\left(\mathrm{cm}^{3}\right), \pi$ is the ratio between the circumference and the diameter of any given circle equaling 3.14159, $r$ is the radius of the weed at its widest point, and $h$ is weed height. Weed aboveground biomass (total dry matter [TDM]) was harvested by hand over a week-long period as the weed species reached their respective physiological maturity. Samples were dried at $70 \mathrm{C}$ to a constant mass and weighed.

Soybean plants were hand harvested in each sub-subplot at physiological maturity from a 4-m length of one row in $76-\mathrm{cm}$ rows or four rows in $19-\mathrm{cm}$ rows. There were two weed-free buffers, 2 and $1 \mathrm{~m}$ long, between each subplot and sub-subplots, respectively, and weedfree buffers of $1.5 \mathrm{~m}$ between sub-subplots. Weed-free 
Table 3. Values for competitive indices (CIs) in WeedSOFT version 9.0, and CI values based on yield loss (YL), weed volume (VOL), and weed dry matter (DM).

\begin{tabular}{|c|c|c|c|c|c|c|c|c|c|c|c|c|c|c|c|c|}
\hline \multirow{3}{*}{$\begin{array}{l}\text { Weed } \\
\text { code }^{\mathrm{a}}\end{array}$} & \multicolumn{4}{|c|}{ WeedSOFT $^{\mathrm{b}}$} & \multicolumn{4}{|c|}{$Y^{c}{ }^{c}$} & \multicolumn{4}{|c|}{$\mathrm{VOL}^{\mathrm{d}}$} & \multicolumn{4}{|c|}{$\mathrm{DM}^{\mathrm{e}}$} \\
\hline & \multicolumn{2}{|c|}{$\mathrm{SRS}^{\mathrm{f}}$} & \multicolumn{2}{|c|}{ RWET $^{\mathrm{g}}$} & \multicolumn{2}{|c|}{ SRS } & \multicolumn{2}{|c|}{ RWET } & \multicolumn{2}{|c|}{$76 \mathrm{~cm}$} & \multicolumn{2}{|c|}{$19 \mathrm{~cm}$} & \multicolumn{2}{|c|}{$76 \mathrm{~cm}$} & \multicolumn{2}{|c|}{$19 \mathrm{~cm}$} \\
\hline & $76 \mathrm{~cm}$ & $19 \mathrm{~cm}$ & VE & V1 & $76 \mathrm{~cm}$ & $19 \mathrm{~cm}$ & VE & V1 & VE & V1 & VE & V1 & VE & V1 & VE & V1 \\
\hline HELAN & 10.0 & 8.0 & 10.0 & 6.0 & 10.0 & 7.8 & 10.0 & 5.7 & 10.0 & 4.0 & 6.0 & 1.0 & 10.0 & 4.0 & 7.0 & 2.0 \\
\hline XANST & 5.0 & 4.0 & 5.0 & 3.0 & 5.5 & 6.7 & 6.8 & 4.4 & 7.8 & 1.5 & 3.0 & 1.0 & 3.6 & 1.0 & 2.5 & 1.0 \\
\hline ABUTH & 4.2 & 3.4 & 4.2 & 2.5 & 3.4 & 2.7 & 5.2 & 3.4 & 1.3 & 0.8 & 2.5 & 0.4 & 2.5 & 0.8 & 1.3 & 0.4 \\
\hline AMBTR & 3.0 & 2.4 & 3.0 & 1.8 & 2.3 & 2.5 & 3.4 & 1.3 & 1.2 & 0.3 & 0.3 & 0.3 & 1.8 & 0.3 & 0.9 & 0.3 \\
\hline AMARE & 2.5 & 2.0 & 2.5 & 1.5 & 3.7 & 3.3 & 4.7 & 1.9 & 1.0 & 0.5 & 0.3 & 0.3 & 1.0 & 0.5 & 0.8 & 0.5 \\
\hline AMATA & 2.5 & 2.0 & 2.5 & 1.5 & 2.4 & 2.0 & 3.7 & 2.3 & 1.0 & 0.3 & 0.5 & 0.3 & 0.5 & 0.3 & 0.3 & 0.3 \\
\hline SETFA & 2.0 & 1.6 & 2.0 & 1.2 & 0.6 & 1.3 & 2.0 & 1.3 & 0.2 & 0.2 & 0.4 & 0.2 & 0.2 & 0.2 & 0.2 & 0.2 \\
\hline SETLU & 1.0 & 0.8 & 1.0 & 0.6 & 0.3 & 1.4 & 2.3 & 0.8 & 0.1 & 0.1 & 0.1 & 0.1 & 0.2 & 0.1 & 0.2 & 0.1 \\
\hline ECHCG & 0.3 & 0.2 & 0.3 & 0.2 & 0.2 & 0.9 & 1.7 & 1.0 & 0.1 & 0.1 & 0.0 & 0.0 & 0.2 & 0.1 & 0.2 & 0.1 \\
\hline
\end{tabular}

\footnotetext{
a Weed code: HELAN, common sunflower; XANST, common cocklebur; ABUTH, velvetleaf; AMBTR, giant ragweed; AMARE, redroot pigweed; AMATA, common waterhemp; SETFA, giant foxtail; SETLU, yellow foxtail; ECHCG, barnyardgrass.

${ }^{\mathrm{b}}$ WeedSOFT, original values of CIs in WeedSOFT version 9.0.

' YL, CI values based on yield loss utilized in WeedSOFT Yield Loss version.

${ }^{a}$ VOL, CI values based on volume utilized in WeedSOFT Volume version.

${ }^{e}$ DM, CI values based on total dry matter utilized in WeedSOFT Dry Matter version.

${ }^{\mathrm{f}} \mathrm{SRS}$, soybean row spacing (76 and $19 \mathrm{~cm}$ ).

${ }^{\mathrm{g}} \mathrm{RWET}$, relative weed emergence time, at soybean emergence (VE) and soybean first trifoliate leaf stage (V1).
}

buffers successfully prevented competition between plants of neighboring sub-subplots. Weed-free yield was harvested from a single soybean row in 76-cm rows and four rows in 19-cm rows, each $4 \mathrm{~m}$ long. Soybean plants were counted and threshed to separate grain. Seeds were then dried at $70 \mathrm{C}$ to a constant mass and weighed. Yield loss was calculated by relating the weed-free yield to the yield from each sub-subplot.

Data Analysis. Analyses of variance were performed using PROC MIXED procedure in SAS (1999) to test significance $(\mathrm{P}<0.05)$ of year, location, soybean row spacing, weed emergence time, weed species, replications, and their interactions with weed TDM, weed volume, and soybean yield loss response variables. Although there were location effects (Hock et al. 2005), our data were combined across sites into one data set, which was recommended as the most appropriate method to generate CI values (White and Coble 1997). CI values were calculated for each weed species based on weed TDM, weed volume, or soybean yield loss using the equation:

$$
\mathrm{CI}_{x}=\left(A_{x} / B_{y}\right) \mathrm{K}
$$

where $\mathrm{CI}_{x}$ is the competitive index of the target weed species $x, A_{x}$ is the measured variable (TDM, weed volume, or soybean yield loss) associated with target $x, B_{y}$ is the measured variable of the most competitive weed,

Table 4. Weed and soybean input parameters utilized in ADVISOR subroutine of WeedSOFT as influenced by soybean row spacing (19 and $76 \mathrm{~cm}$ ) and relative emergence time (VE-V1 and V2-V3). ${ }^{\mathrm{a}}$

\begin{tabular}{|c|c|c|c|c|c|c|c|c|}
\hline \multirow[b]{3}{*}{ Weed code ${ }^{b}$} & \multicolumn{4}{|c|}{ Plant number } & \multicolumn{4}{|c|}{ Plant height } \\
\hline & \multicolumn{2}{|c|}{$19 \mathrm{~cm}$} & \multicolumn{2}{|c|}{$76 \mathrm{~cm}$} & \multicolumn{2}{|c|}{$19 \mathrm{~cm}$} & \multicolumn{2}{|c|}{$76 \mathrm{~cm}$} \\
\hline & VE-V1 & V2-V3 & VE-V1 & V2-V3 & VE-V1 & $\mathrm{V} 2-\mathrm{V} 3$ & VE-V1 & V2-V3 \\
\hline & & $-\mathrm{n}$ & $n^{2}$ & & & & 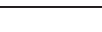 & \\
\hline HELAN & 2.1 & 1.6 & 2.1 & 1.2 & $<15.2$ & $<15.2$ & $<15.2$ & $<15.2$ \\
\hline XANST & 1.8 & 2 & 1.8 & 1.6 & $<5$ & $<5$ & $<5$ & $<5$ \\
\hline ABUTH & 2.4 & 2.2 & 2.4 & 2.3 & $<5$ & $<5$ & $<5$ & $<5$ \\
\hline AMBTR & 1.5 & 2 & 1.3 & 1.6 & $<5$ & $<5$ & $<5$ & $<5$ \\
\hline AMARE & 2.1 & 2.1 & 2 & 1.9 & $<5$ & $<5$ & $<5$ & $<5$ \\
\hline AMATA & 1.8 & 1.9 & 1.9 & 1.8 & $<5$ & $<5$ & $<5$ & $<5$ \\
\hline SETFA & 2.2 & 1.9 & 1.7 & 2 & $<5$ & $<5$ & $<5$ & $<5$ \\
\hline SETLU & 2.2 & 1.9 & 1.8 & 1.9 & $<5$ & $<5$ & $<5$ & $<5$ \\
\hline ECHCG & 1.9 & 2.2 & 1.4 & 1.5 & $<5$ & $<5$ & $<5$ & $<5$ \\
\hline
\end{tabular}

a Abbreviations: VE, soybean emergence; V1, first trifoliate leaf stage; V2, second trifoliate leaf stage; V3, third trifoliate leaf stage.

${ }^{\mathrm{b}}$ Weed code: HELAN, common sunflower; XANST, common cocklebur; ABUTH, velvetleaf; AMBTR, giant ragweed; AMARE, redroot pigweed; AMATA, common waterhemp; SETFA, giant foxtail; SETLU, yellow foxtail; ECHCG, barnyardgrass. 
Table 5. Average error ${ }^{\mathrm{a}}$ (based on years, locations, and replications) between predicted and observed soybean yield loss (\%) in relation to observed yield loss (\%) for WeedSOFT version 9.0 (WS), and for WeedSOFT where competitive indices were based on yield loss (YL), weed volume (VOL), and weed dry matter (DM) as influenced by soybean row spacing (76 and $19 \mathrm{~cm}$ ) and relative weed emergence time (soybean emergence [VE] and first trifoliate leaf stage [V1]). Numbers in parentheses represent the percentage of experimental units that are within $20 \%$ of the observed yield losses.

\begin{tabular}{|c|c|c|c|c|c|c|c|c|}
\hline \multirow[b]{3}{*}{ Weed code ${ }^{\mathrm{b}}$} & \multicolumn{8}{|c|}{$76-\mathrm{cm}$ row } \\
\hline & \multicolumn{4}{|c|}{ VE } & \multicolumn{4}{|c|}{ V1 } \\
\hline & WS & DM & VOL & YL & WS & DM & VOL & YL \\
\hline HELAN & $0.30(71)$ & $0.30(71)$ & $0.30(71)$ & $0.30(71)$ & $3.61(38)$ & $0.13(25)$ & $3.30(38)$ & $6.79(63)$ \\
\hline XANST & $0.51(57)$ & $0.35(60)$ & $0.70(83)$ & $0.90(83)$ & $-0.57(0)$ & $-0.96(0)$ & $-0.88(0)$ & $-0.21(20)$ \\
\hline ABUTH & $0.46(36)$ & $-0.47(0)$ & $-0.67(0)$ & 0.75 & $-0.24(18)$ & $-0.76(18)$ & $-0.92(0)$ & $0.11(27)$ \\
\hline AMBTR & $-2.24(0)$ & $-1.85(0)$ & $-1.51(0)$ & $-3.7(10)$ & $-1.07(0)$ & $-1.50(14)$ & $-1.86(0)$ & $-0.20(29)$ \\
\hline AMARE & $1.13(30)$ & $0.31(20)$ & $-0.21(0)$ & $3.22(20)$ & $3.69(0)$ & $0.63(0)$ & $0.63(0)$ & $7.31(10)$ \\
\hline AMATA & 9.15 (27) & $6.57(9)$ & $2.14(9)$ & $16.54(27)$ & $-5.51(13)$ & $-2.95(13)$ & $-2.74(38)$ & $-6.23(0)$ \\
\hline SETFA & $-17.06(20)$ & $-3.22(0)$ & $-2.66(0)$ & $-24.26(20)$ & $2.58(11)$ & $-0.05(22)$ & $-0.79(11)$ & $4.88(11)$ \\
\hline SETLU & $-0.49(9)$ & $-0.90(0)$ & $-0.97(0)$ & $0.23(9)$ & $-3.62(14)$ & $-1.58(0)$ & $-1.15(0)$ & -5.08 \\
\hline ECHCG & $-0.83(0)$ & $-0.87(0)$ & $-0.96(0)$ & $0.58(22)$ & $-0.96(0)$ & $-0.96(0)$ & $-0.96(0)$ & $-0.45(0)$ \\
\hline
\end{tabular}

${ }^{a}$ For average error, negative and positive values represent under- and overprediction of soybean yield losses, respectively.

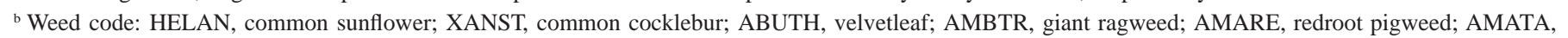
common waterhemp; SETFA, giant foxtail; SETLU, yellow foxtail; ECHCG, barnyardgrass.

and $\mathrm{K}$ is a constant with a value of 10 . The constant $\mathrm{K}$ $=10$ provides a common scale to calculate $\mathrm{CI}$ values that range from 0.01 to 10 and can be used to compare competitiveness among weed species. Common sunflower had the greatest TDM, volume, and reduced soybean yield loss the most when it emerged with soybean in 76$\mathrm{cm}$ rows compared to all other weed species. Thus, common sunflower was considered the most competitive weed species (e.g., $B_{y}$ ) to calculate all other CI values. More details are presented by Hock et al. (2006).

WeedSOFT Input. WeedSOFT performance was evaluated by comparing predicted with observed yield loss for each weed species in two soybean row spacings and two weed emergence times. WeedSOFT was first run using the CI and ACI values in WeedSOFT version 9.0 (WS) (Table 1). Modified CI values obtained from the field experiments were then inserted into WeedSOFT and ADVISOR was rerun to evaluate if new CI values based on soybean yield loss (YL), weed volume (VOL), or weed dry matter (DM) (Table 3) improved predictions of soybean yield loss. Predicted soybean yield loss was obtained by running the ADVISOR module of WeedSOFT using the following inputs: soybean row spacing, soybean weed-free yield, soybean growth stage, weed density, and weed height (Table 4). Weed-free yield was 3.02 and $2.92 \mathrm{Mg} / \mathrm{ha}$ for $19-$ and $76-\mathrm{cm}$ row soybean, respectively.

Statistical Methods and Performance Criterion. WeedSOFT predictive ability was evaluated by comparing predicted and observed soybean yield loss (\%) using the approach outlined by Mitchell and Sheehy (1997). Normalized deviation $\left.\left(\mathrm{P}_{i}-\mathrm{O}_{i}\right) / \mathrm{O}_{i}\right)$, where $\mathrm{P}_{i}$ is the pre- dicted value and $\mathrm{O}_{i}$ is the observed value, was calculated and averaged to provide the average error (AE). The $\mathrm{AE}$ provides an estimate similar to the coefficient of variation. Because experimental errors that are within 10 to $20 \%$ of the mean are commonly acceptable, we arbitrarily assigned an $\mathrm{AE}$ of $|0.2|$ (20\% variation above or below observed yield losses occurring across years and locations) as an indicator of accurate prediction of soybean yield loss.

\section{RESULTS AND DISCUSSION}

WeedSOFT Prediction with Original CIs. WS provided better prediction of soybean yield loss for 19- than 76-cm soybean row spacing and generally was more accurate for weeds emerging at VE than V1 stage (Table 5). Soybean yield loss was predicted accurately for 28 and $33 \%$ of all data sets (years/locations) in 76- and 19$\mathrm{cm}$ rows for weeds emerging at VE stage compared to 10 and $15 \%$ for weeds emerging at V1 stage, respectively. Yield loss predictions were most accurate for early emerging common sunflower and common cocklebur. Soybean yield loss was predicted accurately in 71 and $88 \%$ of all data sets in 76- and $19-\mathrm{cm}$ soybean rows, respectively, when common sunflower emerged at soybean VE stage. Soybean yield loss from common cocklebur was predicted accurately for $71 \%$ of data sets in 19 -cm soybean rows when common cocklebur emerged at soybean V1 stage. Poor yield loss predictions occurred when common sunflower emerged at soybean V1 stage. When common sunflower emerged at V1 soybean stage, prediction of yield loss was accurate in 38 and $25 \%$ of data sets for 76- and 19-cm soybean rows, respectively. 
WEED TECHNOLOGY

Table 5. Extended.

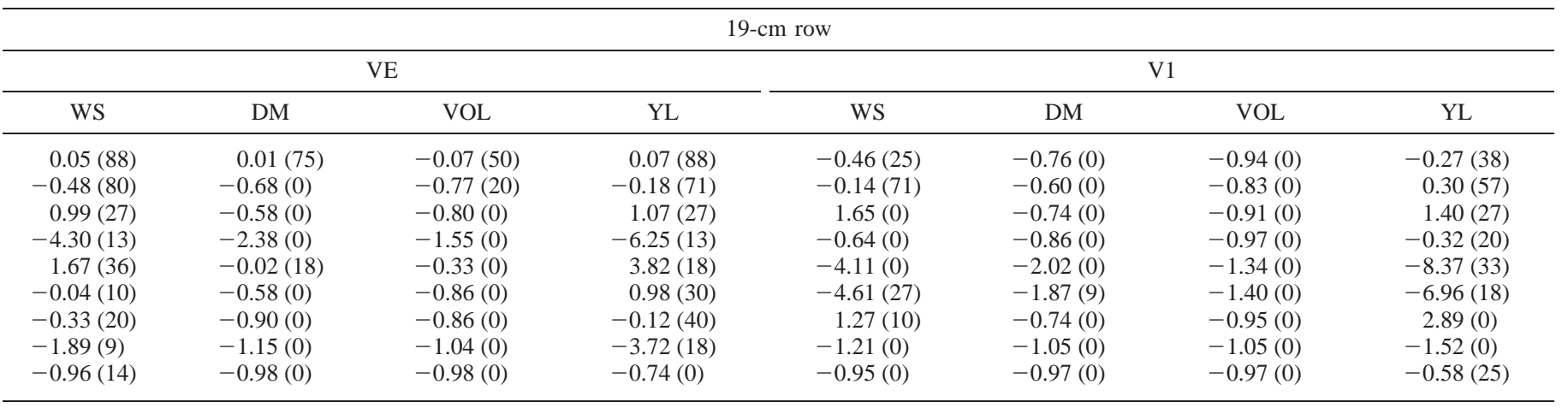

Prediction of soybean yield loss was poor for other weed species tested (Table 5).

WeedSOFT Prediction with New CI values. WeedSOFT provided slightly improved yield loss predictions with YL compared to WS. Yield loss by common sunflower emerging at V1 stage in $76-\mathrm{cm}$ rows was predicted with $63 \%$ of accuracy with YL compared to $38 \%$ with WS. Similar response was observed with other species. Soybean yield loss caused by velvetleaf that emerged at V1 stage in $76-\mathrm{cm}$ rows was predicted accurately for 27 and $18 \%$ of experimental units by YL and WS, respectively. Soybean yield loss predictions were improved for grassy species with YL compared to WS. When weeds emerged at VE crop stage in $19-\mathrm{cm}$ rows, yield loss caused by giant foxtail was predicted accurately in 40 and $20 \%$ of experimental units with YL and WS, respectively (Table 5). Differences in the predictive abilities may be due to different values of ACI modifiers used in YL compared to WS (Table 1). YL has ACI modifiers that were species specific and based on actual field data of the effects of row spacing and weed emergence time on soybean yield loss, whereas the ACI modifiers in WS were generic and based on expert opinion.

Overall accuracy of WeedSOFT was greater by using YL than the DM or VOL. Soybean yield loss prediction caused by common waterhemp emerging at VE stage in 76-cm rows was 27, 9, and 9\% accurate for all data sets by YL, VOL, and DM, respectively (Table 5). Prediction of yield loss also was more accurate in YL than VOL or DM for weeds emerging at soybean V1 stage. Prediction of soybean yield loss caused by common sunflower was 63,38 , and $25 \%$ accurate in $76-\mathrm{cm}$ rows as well as 38,0 , and $0 \%$ accurate in $19-\mathrm{cm}$ rows for $\mathrm{YL}$, VOL, and DM, respectively. Similar trends occurred for other weed species. Yield loss predictions from giant foxtail emerging at VE stage was $40 \%$ accurate for YL but only $20 \%$ for WS and 0\% for both VOL and DM (Table 5). Yield loss prediction was not accurate (0\%) for other weed species for VOL and DM. Moreover, DM and VOL underpredicted yield loss for every species.

WeedSOFT predictions also were compared between the two times of weed emergence. Generally, yield loss predictions by $\mathrm{YL}$ were improved for weeds emerging at VE compared to V1 stage in both row spacings. In 76-cm rows, YL improved yield loss predictions for three species emerging at V1 stage, compared to nine weed species emerging at VE stage. The same was true between the two emergence times in 19-cm rows. Similar trends occurred for WS, DM, and VOL versions. Poor predictions for the VOL and DM versions may be attributed to the lower CI values compared to WS and YL versions. The CI values were much smaller for VOL and DM because of more variable dry matter and plant volume compared to yield loss (Hock et al. 2006).

The results presented in this paper indicate that using new CIs based on soybean yield loss provided some, but not major, improvements in WeedSOFT for predicting soybean yield loss. We believe that improvements are needed in other functions WeedSOFT uses to calculate soybean yield loss. One area that we suggest for further testing is the yield loss function for each weed species. The yield loss function, part of the ADVISOR subroutine, is represented with a modified rectangular hyperbola with both linear and nonlinear components (Neeser et al. 2004). This function is generic in nature with crossover value (e.g., TCL value of 50 for soybean) at which yield loss enters a nonlinear phase regardless of weed species composition. The value of TCL $=50$ for soybean was chosen based on area of influence studies for 
common cocklebur (Barrentine and Oliver 1977; Gonsolus 1986), which showed that weeds start interfering with each other as their densities increase (Wilkerson et al. 1991). This response may not occur at the same TCL for all weed species, especially velvetleaf, which has been shown to allocate its leaf area to the upper portion of the plant under shading conditions (Regnier and Harrison 1993). In contrast, cocklebur has been described as a relatively "stable" species; its canopy architecture did not change in response to light regime (Regnier and Stoller 1989). This finding may indicate that the yield loss function needs to be species specific. We suggest that when there is a mix of weed species that are less plastic, the yield loss function may be correct the way it is (e.g., generic). However, if there is a mix of weeds with varying levels of plasticity, the shape of yield loss functions would change. Further testing is needed to test such hypotheses.

This work also demonstrated that the current version of WeedSOFT does not provide satisfactory yield loss predictions. WeedSOFT was not specifically designed to model weed-crop interference. Instead, its purpose is to provide a "best estimate" of crop yield loss due to weed interference for the sole purpose of recommending the most cost-effective weed control options. Results from a regional project suggested that WeedSOFT provided excellent herbicide efficacy predictions on tested weed species, which indicated a good potential for practical use of this software for herbicide recommendations (S. Z. Knezevic, unpublished data). In addition, future improvements in our understanding of crop-weed competition also may provide basis for further improvements in WeedSOFT.

\section{ACKNOWLEDGMENTS}

Partial support of this work was provided by U.S. Department of Agriculture CSREES RAMP award 200161101-11100. We thank Lynn Bills for his computer programming contributions.

\section{LITERATURE CITED}

Barrentine, W. L. and L. R. Oliver. 1977. Competition, Threshold Levels, and Control of Cocklebur in Soybeans. Mississippi Agricultural and Forestry Experiment Station Technical Bulletin 83. 17 p.

Bauer, T. A., D. A. Mortensen, G. A. Wicks, T. A. Hayden, and A. R. Martin. 1991. Environmental variability associated with economic thresholds for soybeans. Weed Sci. 39:564-569.
Chikoye, D. and C. J. Swanton. 1995. Evaluation of three empirical models depicting Ambrosia artemisiifolia competition in white bean. Weed Res. 35:421-428.

Coble, H. D. and D. A. Mortensen. 1992. The threshold concept and its application to weed science. Weed Technol. 6:191-195.

Cousens, R. 1985. A simple model relating yield loss to weed density. Ann. Appl. Biol. 2:239-252.

Cousens, R., L. G. Firbank, A. M. Mortimer, and R.G.R. Smith. 1988. Variability in the relationship between crop yield and weed density for winter wheat and Bromus sterilis. J. Appl. Ecol. 25:1033-1044.

Gonsolus, J. L. 1986. Reciprocal Interference Effects Between Weeds and Soybeans (Glycine max) measured by area of influence methodology. Ph.D. dissertation. North Carolina State University, Raleigh, NC. 67 p.

Hock, S. M., S. Z. Knezevic, A. R. Martin, and J. L. Lindquist. 2006. Soybean row spacing and weed emergence time influence weed competitiveness and competitive indices. Weed Sci. 54:38-46.

Knezevic, S. Z., S. F. Weise, and C. J. Swanton. 1994. Interference of redroot pigweed (Amaranthus retroflexus) in corn (Zea mays). Weed Sci. 42:568 573.

Knezevic, S. Z., S. F. Weise, and C. J. Swanton. 1995. Comparison of empirical models depicting density of Amaranthus retroflexus L. and relative leaf area as predictors of yield loss in maize. Weed Res. 35:207214.

Lindquist, J. L. and D. A. Mortensen. 1999. Ecophysiological characteristics of four maize hybrids and Abutilon theophrasti. Weed Res. 39:271-285.

Lindquist, J. L., D. A. Mortensen, S. A. Clay, R. Schmenk, J. J. Kells, K. Howatt, and P. Westra. 1996. Stability of corn (Zea mays)-velvetleaf (Abutilon theophrasti) interference relationships. Weed Sci. 44:309-313.

Lotz, L.A.P., S. Christensen, D. Cloutier, et al. 1996. Prediction of the competitive effects of weeds on crop yields based on the relative leaf area of weeds. Weed Res. 36:93-101.

Mitchell, P. L. and J. E. Sheehy. 1997. Comparison of predictions and observations to assess model performance: a method of empirical validation. In M. J. Kropff, P. S. Teng, P. K. Aggarwad, J. Bouma, B.A.M. Bouman, J. W. Jones, and H. H. van Laar, eds. Applications of Systems Approaches at the Field Level. London: Kluwar Academic. Pp. 437-450.

Mortensen, D. A., A. R. Martin, F. W. Roeth, T. E. Harvill, R. W. Klein, G. A. Wicks, R. G. Wilson, D. L. Holshouser, and J. W. McNamara. 1993. NebraskaHERB Version 3.0 User's Manual. Lincoln, NE: Department of Agronomy, University of Nebraska. $10 \mathrm{p}$.

Neeser, C., J. A. Dille, G. Krishnan, D. A. Mortensen, J. T. Rawlinson, A. R. Martin, and L. B. Bills. 2004. WeedSOFT ${ }^{\circledR}$ : a weed management decision support system. Weed Sci. 52:115-122.

Rankins, A., D. R. Shaw, and J. D. Byrd. 1998. HERB and MSU-HERB field validation for soybean (Glycine max) weed control in Mississippi. Weed Technol. 12:88-96.

Regnier, E. E. and S. K. Harrison. 1993. Compensatory responses of common cocklebur (Xanthium strumarium) and velvetleaf (Abutilon theophrasti) to partial shading. Weed Sci. 41:541-547.

Regnier, E. E. and E. W. Stoller. 1989. The effects of soybean (Glycine max) interference on the canopy architecture of common cocklebur (Xanthium strumarium), jimsonweed (Datura stramonium), and velvetleaf (Abutilon theophrasti). Weed Sci. 37:187-195.

Ritchie, S. W., J. J. Hanway, and G. O. Benson. 1993. How a soybean plant develops. Spec. Rep. 53. Ames, IA: Iowa State University.

[SAS] Statistical Analysis System. 1999. SAS OnLine Doc, Version 8. Cary, NC: Statistical Analysis Systems Institute.

Sturgill, M. C., G. G. Wilkerson, J. Wilcut, A. C. Bennett, and G. S. Buol 2001. HADSS 2001 User's Manual. Research Bulletin 192. Raleigh, NC: Crop Science Department, North Carolina State University.

White, A. D. and H. D. Coble. 1997. Validation of HERB for use in peanut (Arachis hypogaea). Weed Technol. 11:573-579.

Wiles, L. J., R. P. King, E. E. Schweizer, D. W. Lybecker, and S. M. Swinton. 1996. GWM: general weed management model. Agric. Syst. 50:335-376.

Wilkerson, G. G., S. A. Modena, and H. D. Coble. 1991. HERB: decision model for postemergence weed control in soybean. Agron. J. 83:413417. 